AperTO - Archivio Istituzionale Open Access dell'Università di Torino

\title{
Chemico-physical characterisation and in vivo biocompatibility assessment of DLC-coated coronary stents.
}

\section{This is the author's manuscript}

Original Citation:

Availability:

This version is available http://hdl.handle.net/2318/140003

since

Published version:

DOI:10.1007/s00216-012-6449-x

Terms of use:

Open Access

Anyone can freely access the full text of works made available as "Open Access". Works made available under a Creative Commons license can be used according to the terms and conditions of said license. Use of all other works requires consent of the right holder (author or publisher) if not exempted from copyright protection by the applicable law. 


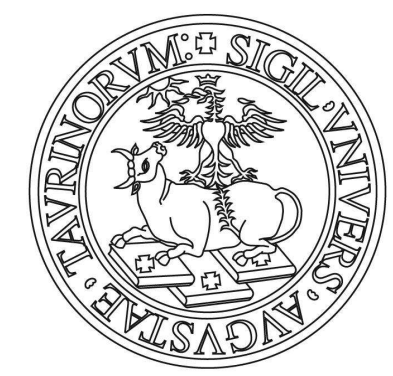

\section{UNIVERSITÀ DEGLI STUDI DI TORINO}

This is an author version of the contribution published on:

Questa è la versione dell'autore dell'opera:

Chemico-physical characterization and in vivo biocompatibility assessment of DLCcoated coronary stents, Analytical and Bioanalytical Chemistry, 405 (1), 2013, doi: 10.1007/s00216-012-6449-x

The definitive version is available at:

La versione definitiva è disponibile alla URL:

http://link.springer.com/article/10.1007\%2Fs00216-012-6449-x 


\title{
Chemico-physical characterisation and in vivo biocompatibility assessment of DLC-coated coronary stents
}

Micaela Castellino \& Vlad Stolojan \& Alessandro Virga \& Massimo Rovere \& Karine Cabiale \& Marco R. Galloni \& Alberto Tagliaferro

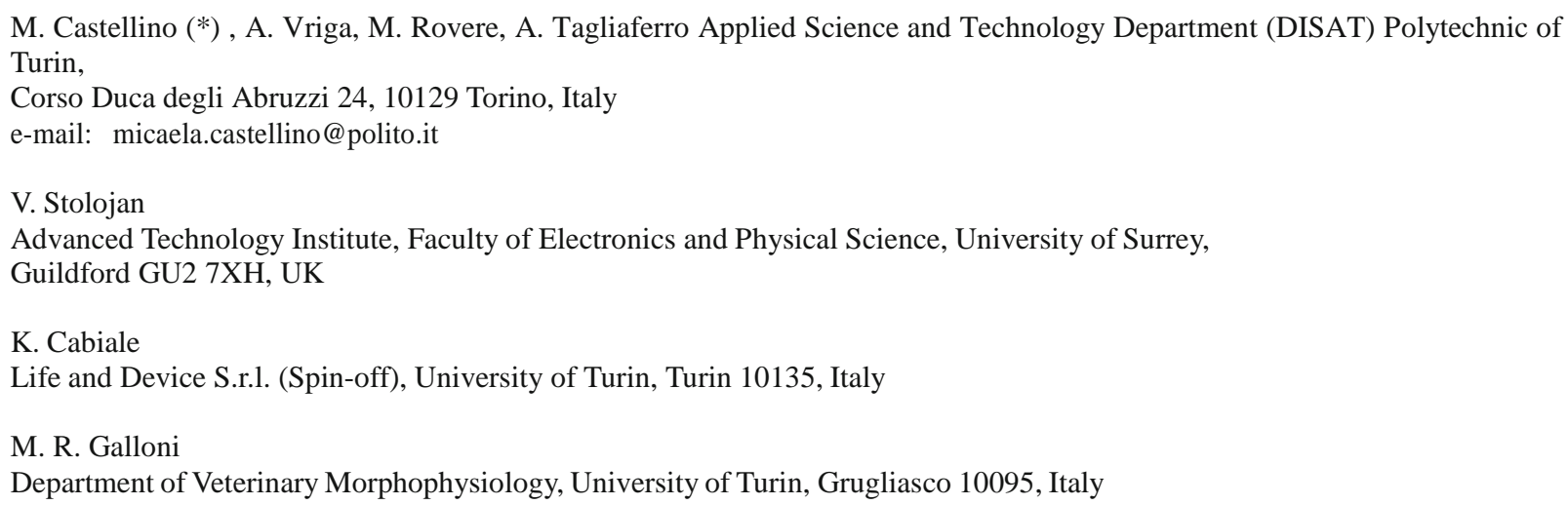

\begin{abstract}
The vast majority of stent thrombosis occurs in the acute and sub-acute phases and is more common in patients with acute coronary syndromes, due to the thrombotic milieu where stent struts are positioned. Stent thrombosis is likely due to incomplete tissue coverage of metallic stents as the contact between metallic stents and blood elements may lead to platelet adhesion and trigger vessel thrombosis. If a stent is covered after 7 days, the risk that it will be found uncovered at later stages is very low $(<1 \%)$. In this article, we demonstrate that diamond-like carbon (DLC) coatings, deposited by physical vapour deposition, promote rapid endothelisation of coronary stent devices, with very low platelets activation, reducing thrombotic clots. We relate these behaviours to the surface and bulk material properties of the DLC films, subjected to a comprehensive chemico-physical characterisation using several techniques (X-ray photoelectron spectroscopy, atomic force microscopy, field-emission scanning electron microscope, transmission electron microscopy combined with electron energy loss spectroscopy, Raman and dispersive X-ray spectroscopy). In vivo studies, conducted on 24 pigs, have shown complete endothelisation after 7 days, with no fibrin mesh and with only rare monocytes scattered on the endothelial layer while 30 and 180 days tests have shown reduced inflammatory activation and a complete stabilisation of the vessel healing, with a minimal neointimal proliferation. The integral and permanent DLC film coating improves haemo- and bio-compatibility and leads to an excellent early vessel healing of the stent whilst the extremely thin strut thickness reduces the amount of late neointima and consequently the risk of late restenosis. These data should translate into a reduced acute and subacute stent thrombosis.
\end{abstract}

Keywords Biomaterials Interface/surface analysis Thin films X-ray spectroscopy (XPS/XRF/EDX) Atomic force microscopy (AFM) Electron/ion microprobe

\section{Introduction}


Every time a foreign body comes into contact with a human corpus, the response of the immune defence system is proportional to the alarm bell that has been activated. Nevertheless, it is sometimes necessary to include foreign materials inside human organs and tissues, in order to solve health problems. This happens, for instance, when we are dealing with cardiovascular diseases, which are tackled mainly by implanting valves and/or coronary stents. For this reason, after having chosen the best shape and size, in order to be as little invasive as possible, it is necessary to focus on the type of material that can be the best solution to mimic body tissue, to prevent inflammations and not be rejected. Literature $[1,2]$ shows that such materials have to fulfil several requirements, such as to possess appropriate mechanical properties and surface characteristics, excellent haemocompatibility and good biocompatibility. Carbon- based materials have been considered, in the last decades, as one of the most biocompatible compounds, and they have been used as coating materials for bare metallic structures since they are chemically inert and they can reduce metal- ion release from the inner substrates [3]. Among all the carbon allotropes, diamond-like carbon (DLC) has high hardness, low friction coefficient, low wear rate, strong adhesion to the substrate and a smooth surface finishing [4,5]. These properties make it ideal as a coating for cardiovascular (heart valves and peripheral stents), orthopaedic and dental applications [6-8]. The remarkable properties of DLC derive from its amorphous atomic structure, and the ratio of $\mathrm{sp}^{2}$ - to $\mathrm{sp}^{3}$-bonded carbon, that is strongly correlated with the deposition technique used. Such techniques fall into two broad categories, depending on whether the process is primarily chemical or physical. For the first category chemical vapour deposition (CVD) is the most utilised, while for the second one the possibilities are multiples, including ion beam deposition, filtered cathodic vacuum arc deposition, DC and RF sputtering, pulsed laser deposition, and plasma immersion ion implantation $[9,10]$. Moreover, deposition at low temperatures allow the growth of DLC thin films onto temperature-sensitive substrates, like polymers and metals with low melting points [11]. In order to be sure about DLC biocompatibility, several studies have been accomplished on various forms of these carbon films, from blood compatibility $[12,13]$ to cell activity and cytotoxic effects surveys, with several cell culture lines $[14,15]$. A low degree of platelets spread out on DLC-coated medical devices has been associated with a low degree of roughness and a hydrophobic behaviour of the surface [16]. Furthermore, it has been proved that DLC thin films can prolong the clotting time, suppress the plate- lets and complement convertase activation, when compared with reference polymer substrates or Si wafers [17]. Another important aspect is the non-activation of inflammatory signals that can produce pathological responses to the implants such as the formation of blood clots [18, 19]. Previous investigations of DLC as a biomaterial have focused mainly on the biological performance of DLC coatings by means of cell cultures or cytotoxicity studies [20,21], without a detailed understanding of the composition and structural effects of the coating for specific biomedical applications. Recently, the attention has been focused mainly on the characterisation of the DLC surface, in order to propose an explanation about the relationship between the physicochemical properties of the surface of DLCs and the biological response [22, 23]. In this outlook, our scope is to provide an extensive characterisation of a DLC coating (iCarbofilm ${ }^{\mathrm{TM}}$ ), deposited on cobalt chromium alloy coronary stents. For this reason, we investigate the surface and bulk physical properties of the DLC, as well as the pro-healing effect, based on two biological response parameters, rapid endothelisation and long-term inflammatory responses. 


\section{Materials and methods}

\section{Materials}

Twenty-six Avantgarde ${ }^{\mathrm{TM}}$ stents, manufactured by CID S.p.A. (Saluggia, VC, Italy), were prepared to assess both the physical properties of the carbon-coated stent surfaces and the pro- healing effect, by means of implantation in porcine native coronary arteries. The Avantgarde ${ }^{\mathrm{TM}}$ stent is a cobalt-chromium (Co-Cr; L605) alloy stent, coated with a thin film $(<0.3 \mu \mathrm{m})$ of high-density pure carbon. All Avantgarde ${ }^{\mathrm{TM}}$ stents were mirror-like polished and cleaned prior to coating. The carbon film (iCarbofilm ${ }^{\mathrm{TM}}$ ) was deposited on the stent surface by means of a physical vapour deposition (PVD) at low temperatures $\left(\mathrm{T}<100{ }^{\circ} \mathrm{C}\right)$ resulting in a very high adhesion force to the alloy substrate $(>70 \mathrm{MPa})$, as measured with the pulling test (ASTM D4541 and ISO4624). Two Avantgarde ${ }^{\mathrm{TM}}$ stents, reduced in small pieces $(<5 \mathrm{~mm})$ using sharp surgical scissors, were dedicated to chemico-physical examinations, while the remaining 24 were implanted in porcine coronary arteries for in vivo assessment of endothelisation at 7 days and tissue inflammatory response at 30 and 180 days. Avantgarde ${ }^{\text {TM }}$ stents were compared with 24 clinical grade Co-Cr stents (Multi-Link Vision, Abbott Vascular Laboratories, USA), used as the control group.

\section{Coating characterisation}

\section{X-ray photoelectron spectroscopy}

A Thermo Scientific Sigma Probe X-ray photoelectron spec- troscopy (XPS) instrument, equipped with a monochromatic $\mathrm{Al} \mathrm{X}$-ray source (1486.6 eV energy, $15 \mathrm{kV}$ voltage and $1 \mathrm{~mA}$ anode current), has been used to investigate surface chemical composition and carbon allotrope state of the DLC thin film. A spot size of $100 \mu \mathrm{m}$ has been used in order to collect the signal only from the coated stent structure. Different pass energy values have been used for the various types of spectra acquisition: $300 \mathrm{eV}$ for survey spectra, $50 \mathrm{eV}$ for $\mathrm{C} 1 \mathrm{~s}$ peak, $100 \mathrm{eV}$ for the valence band (VB) region and $20 \mathrm{eV}$ for the $\mathrm{O} 1 \mathrm{~s}$ peak.

Field emission scanning electron microscope combined with energy-dispersive X-ray spectroscopy

A ZEISS SUPRA 40 field-emission scanning electron microscope (FESEM) has been used to analyse the sample surface, to check its roughness and morphology. As the sample was conducting, no special charge suppression was necessary. An OXFORD INCA ENERGY 450 energy-dispersive X-ray spectroscopy (EDX), equipped with a liquid-nitrogen cooled $\mathrm{Si}(\mathrm{Li})$ detector (with guaranteed resolution of $133 \mathrm{eV}$ at $\mathrm{MnK} \alpha, 70 \mathrm{eV}$ at $\mathrm{FK} \alpha$ and $66 \mathrm{eV}$ at $\mathrm{CK} \alpha$ ), has been used to obtain information regarding the DLC film chemical composition.

\section{Raman spectroscopy}

The Raman spectra were recorded using a Renishaw inVia confocal Raman spectrometer coupled to a Leica microscope with a $\times 50$ objective in backscattering geometry. We used two laser wavelengths for analysis, 514 and $458 \mathrm{~nm}$, produced using an argon-krypton laser with a holographic notch filter with a grating of 1,800 lines/mm for $514 \mathrm{~nm}$ line and 2,400 lines/mm for the $458 \mathrm{~nm}$ one. The backscattered Raman photons were collected by a thermoelectrically cooled $\left(-60^{\circ} \mathrm{C}\right) \mathrm{CCD}$ detector. The scattering 
spectra were recorded in the range of $0-3,500 \mathrm{~cm}^{-1}$, in one acquisition, $30 \mathrm{~s}$ accumulation time and 0.7 $\mathrm{mW}$ beam intensity at the sample surface.

Atomic force microscopy

The film surface morphology has been investigated in ambient atmosphere with a Digital Instruments NanoScope IIIa atomic force microscope (AFM), operating in tapping mode, using NanoScope Software 6.1 version. Each small piece obtained from cutting the stent, was attached with a strong adhesive tape to a sample holder, in order to hold it firmly during the tip scan.

Transmission electron microscopy combined with electron energy loss spectroscopy

The $\mathrm{sp}^{2} / \mathrm{sp}^{3}$ bond ratio of the DLC coating was measured using a Philips CM200 transmission electron microscopy (TEM; LaB6 filament, $200 \mathrm{kV}$ accelerating voltage) fitted with a Gatan Imaging Filter (GIF; 2000 with a $1 \times 1 \mathrm{~K}$ charge-coupled device), which allows for electron energy loss spectroscopy (EELS). A carbon film portion has been detached mechanically from each sample by lapping the metal part by means of fine-grit sandpaper.

In vivo studies

The tests were conducted on 24 pigs. All animals were randomly implanted with one Avantgarde and one control stent (right coronary artery and left-descending anterior coronary artery). They were anaesthetised and treated with antibiotics, then heparinised (150 UI/kg) by intra-arterial route $(\mathrm{ACT}>300 \mathrm{~s})$. An arterial access was made in the common right carotid artery by means of a $7 \mathrm{~F}$ introducer. A Judkins or Amplaz type guide catheter was inserted through the introducer by means of a $\mathrm{J}$ guide wire, size 0.035 in. The coronary ostium was reached with injection of contrast media. The investigational devices were implanted through a 6-F guide catheter over a 0.014in. guide wire. The operation was monitored by angiography; the device was driven until the implantation site was reached, then it was expanded by appropriate pressure (vessel/device diameter ratio of 1:1.1) until it was well apposed to the vessel wall. The antiplatelet treatment was limited to aspirin from 2 days before the procedure to the seventh post- procedural day, then suspended. No supplementary antiplatelet drugs (ticlopidine or clopidogrel) were administered. At the end of the prescribed follow-up period, all animals underwent a further angiographic examination in order to assess the vessel patency. The animals were anesthetised with intramuscular injections of $2 \mathrm{mg} / \mathrm{kg}$ of ketamine and $2 \mathrm{mg} / \mathrm{kg}$ of xylazine and by inhaling $1 \%$ isofluoran. A 7-F introducer was positioned in the left carotid artery and a follow-up angiography was carried out on the implanted coronaries, using a similar method to the one described above. The animals received 14,000 IU of intravenously administered heparin. The animals were then euthanised by an intravenous injection of barbiturate $(60 \mathrm{mg} / \mathrm{kg})$ through the jugular access, following the 'AVMA guidelines on Euthanasia (June 2007)'. After the explants, the heart was submitted to X-ray analysis to confirm the stent location, following which the coronary trees were perfused with heparinised physiological solution. When the perfused liquid looked free from haematic traces, the coronaries were fixed with a solution of formaldehyde at $4 \%$ at $150 \mathrm{mmHg}$ pressure. The coronary vessels were then carefully dissected from the epicardial surface, preserving the artery size and shape. Then the samples were formalin postfixed. The stents explanted at 7 days were processed for scanning electron microscopy (SEM) to 
assess endothelisation. Stent segments for SEM analysis were longitudinally cut, critical point dried and, before gold coating, pictures were taken of each half-stent by a stereo microscope at high magnification. After the gold coating $(5 \mathrm{~nm})$, which was necessary because the stent surface covered by the endothelium was no longer conductive, the stent segments were analysed by SEM at $\times 35$ and $\times 250$ magnification (or higher if necessary), to observe the surface of the stent. Endothelisation was calculated from the stereoscopic images by measuring the non-endothelised strut surfaces, over the total extent of strut surfaces. The stented coronary segments at 30 and 180 days were tested for methyl-methacrylate embedding. A representative number of $5 \mu \mathrm{m}$ sections were cut perpendicularly to the long axis of the vessel by a precision microtome, at the proximal, mid- and distal stent level. Histological sections were stained with haematoxylin and eosin and Movat Pentachromic. Photomicrographs were taken for each segment of interest, in order to process for histological and histomorphometric analysis. Endothelisa- tion percentage and histomorphometric variables were measured and analysed by Image-Pro Plus software (Media Cybernetics Inc. Bethesda, MD).

Fig. 1 XPS C1s peak high-resolution spectrum showing the deconvolution made with three Voigt functions, which give the contribution of the $\mathrm{sp}^{2}$, $\mathrm{sp}^{3}$ and $\mathrm{C}-\mathrm{O}$ chemical shifts. DLC VB spectrum has been reported in the inset, together with a diamond reference spectrum taken from [32], showing the absence of the diamond fingerprint peak at $13 \mathrm{eV}$ (peak II)
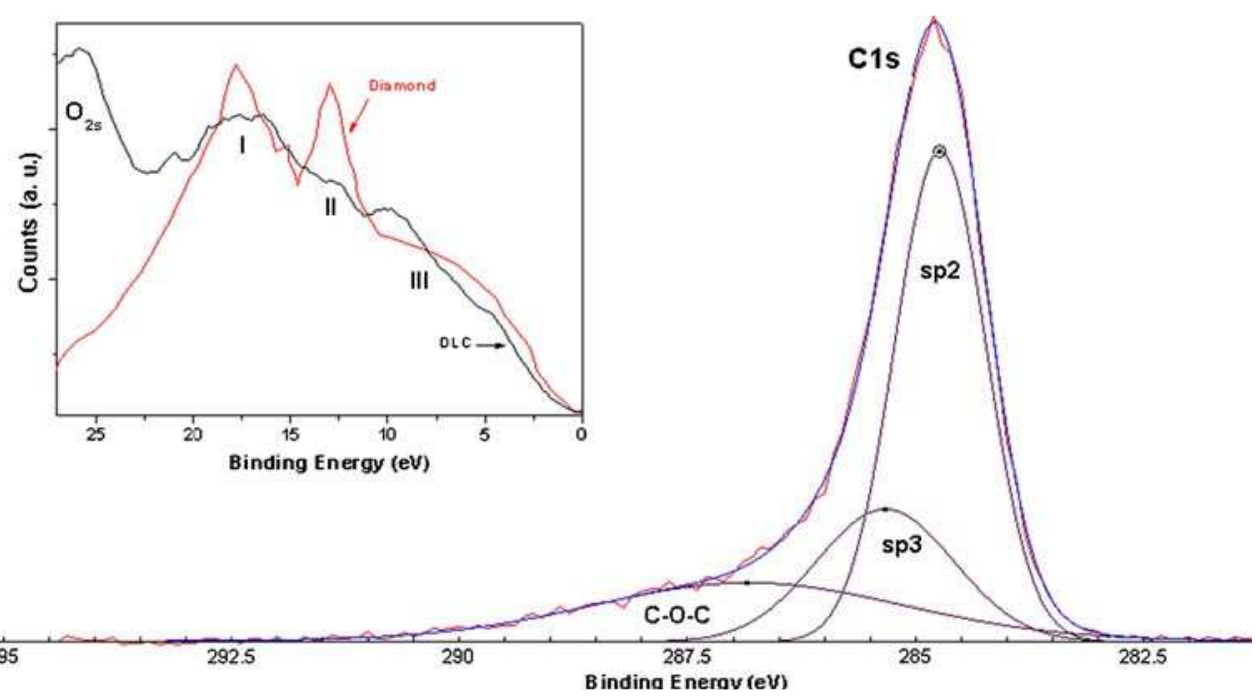

\section{Results and discussion}

Stent analysis pre-implantation

In order to understand how the growth parameters affected the film morphology and its biocompatible behaviour, first of all we have conducted a complete surface and bulk characterisation of the DLC film [24]. We performed XPS analysis on two different locations, for both surfaces (inner and outer) of the stents. Survey spectra show two main photoelectronic peaks at 531 (O1s) and 285 eV (C1s) and Auger peaks at $1,000 \mathrm{eV}(\mathrm{O} \mathrm{KLL})$. We detected also some small peaks indicating surface contamination $(\mathrm{N}, \mathrm{Fe}, \mathrm{Na}, \mathrm{Si}$ and $\mathrm{Cl})$. Relative atomic concentration has been evaluated after subtracting the background with a Shirley function [25] obtaining 15-20\% for O1s and less than 3 $\%$ for the contaminants. C1s high-resolution spectra (see Fig. 1) have been decomposed, using three Voigt-shaped components, in order to evaluate $\mathrm{sp}^{2} / \mathrm{sp}^{3}$ ratio. After an exhaustive research in literature [26-29], we attributed the three peaks to the following carbon bonds: $284.2-284.5 \mathrm{eV}^{2} \mathrm{sp}^{2}$ 
component; 285.2-285.6 eV to $\mathrm{sp}^{3}$-bonded carbon and 286.1-288.1 eV to chemical shifts due to C-O bonds (C-O-C, $\mathrm{C} 0 \mathrm{O}$ etc.). The $\mathrm{sp}^{3}$ amount is roughly constant (from 35.4 to $39.7 \%$ ) in all investigated locations. This can be attributed to a chemically homogeneous surface characterised by regions which do not differ very much.

It is interesting to note that, in the case of amorphous carbon materials that have both $\mathrm{sp}^{2}$ and $\mathrm{sp}^{3}$ atoms, the study of the $\mathrm{C} 1 \mathrm{~s}$ spectrum can be supported focusing the attention onto another region of the XPS spectrum: the VB [30,31].

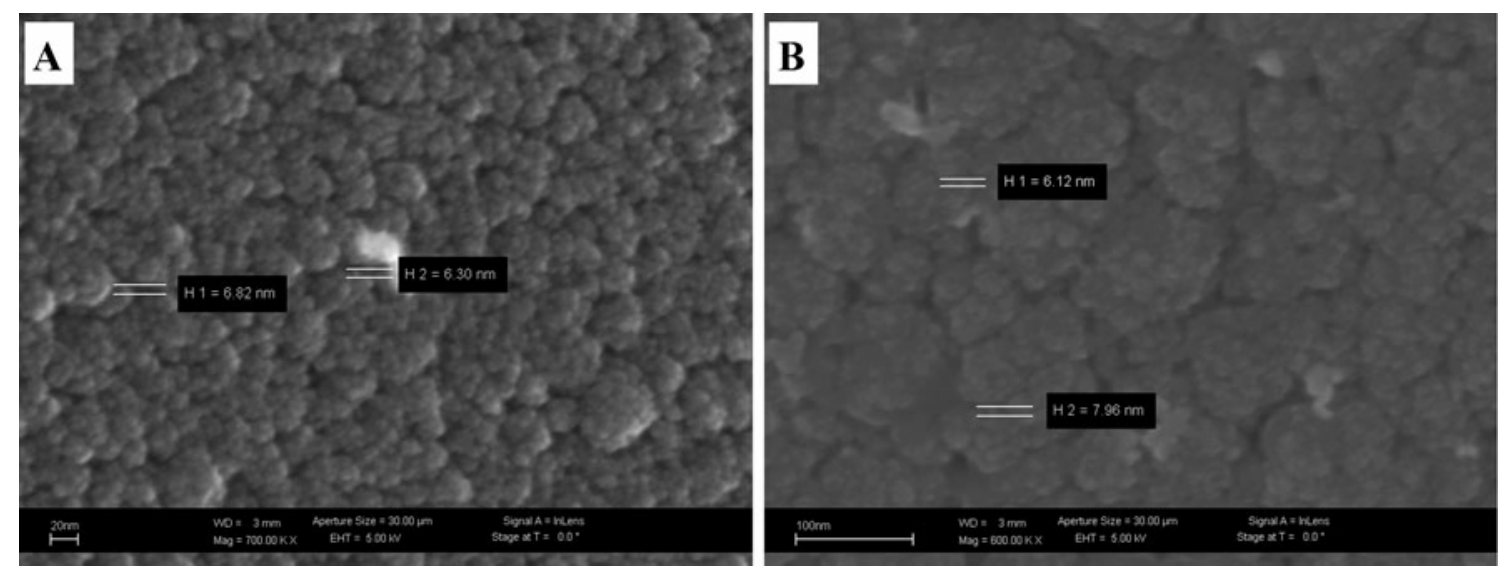

Fig. 2 The FESEM images of the stent inner (A) and outer (B) side, showing the cauliflower structures due to the microstructures and the small round shapes due to the nanostructures

Fig. 3 AFM maps taken at two scan range, $3.3 \times 3.3$ $\mu \mathrm{m}^{2}$ (A) and $370 \times 370$

$\mathrm{nm}^{2}$ (B). The first one shows the uniformity of the grains distribution, while the second one shows the bigger and smaller structures, as shown by FESEM
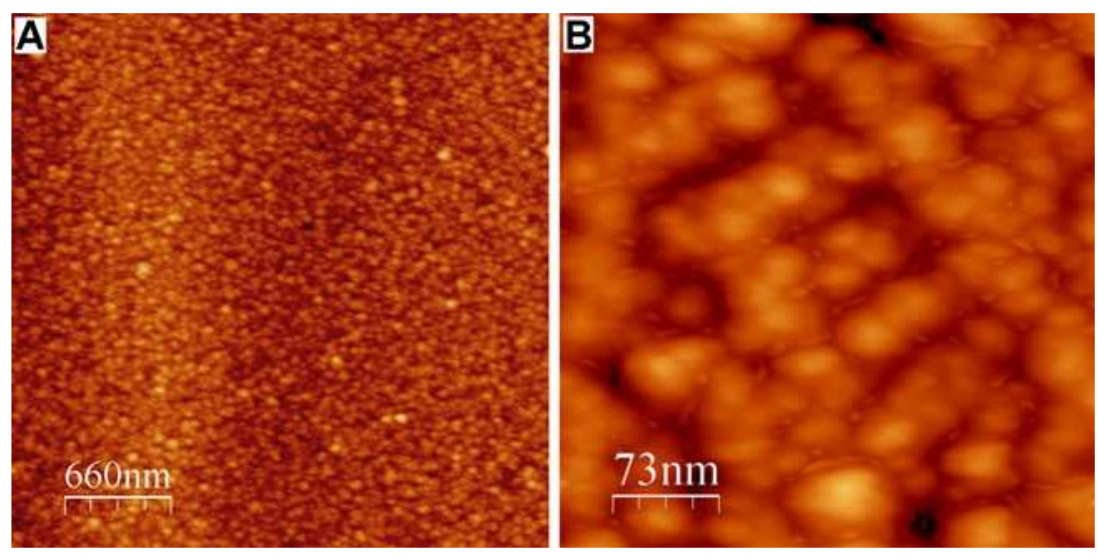

McFeely et al. [32] have conducted an accurate study to this purpose, analysing the diamond, graphite and amorphous carbon VB. It is possible to distinguish three main features: a moderately broad and intense peak in the range between 15 and $21 \mathrm{eV}$ (peak I), a less-intense peak between 10 and $15 \mathrm{eV}$ (peak II) and a broad and less-defined structure, extending from 10 to $13 \mathrm{eV}$ to the cut-off energy (peak III). The VB arise predominantly from $2 \mathrm{~s}$ and $2 \mathrm{p}$ atomic states. The intensity of peak I is greater than peak III one mainly due to the large difference in the photoemission cross-section ratio as $\sigma ð 2 \mathrm{sP}=\sigma ð 2 \mathrm{pP} 1 / 413$ [33]. Since peak II is negligible in graphite and amorphous carbon VB spectra, we conclude that it is due to $\mathrm{sp}^{3}$ hybrids bonds. In our stent VB spectrum (see Fig. 1 inset), the three 
peaks (I, II and III) are not so evident and the overall spectrum is similar to the glassy carbon VB reported by McFeely [32]. The presence of the $\mathrm{O} 2 \mathrm{~s}$ peak at $26 \mathrm{eV}$ makes a full decompo- sition of the signal quite unreliable because of the overlap between it and peak I. Hence, an estimate of $\mathrm{sp}^{2} / \mathrm{sp}^{3}$ ratio from this spectrum will be affected by a very large error bar.

To further test our coatings' surfaces, FESEM, combined with EDX, was used to detect the surface micro morphology (see Fig. 2) and bulk chemical composition [34]. We can observe two types of micro and nanostructures: the first are 'cauliflower like' and their average dimensions vary depending on the location on the stent (from 20 to $60 \mathrm{~nm}$ on inner and from 50 to $120 \mathrm{~nm}$ on outer surfaces) while the latter appear to be constant (around $6 \mathrm{~nm}$ ) independently from side and zone. EDX spectra have shown the presence of several chemical elements, apart from $\mathrm{C}$ and $\mathrm{O},(\mathrm{Co}, \mathrm{Fe}, \mathrm{Ni}$, $\mathrm{W}$ and $\mathrm{Cr}$ ) which correspond to the L605 alloy chemical composition.

Table 1 Raman Id/Ig ratios calculated for inside and outside scanned areas and grain sizes calculated via Tuinstra formula [37], with their relative errors $(\sigma)$

\begin{tabular}{|c|c|c|c|c|}
\hline Surface & $\mathrm{Id} / \mathrm{Ig}$ & $\sigma(\mathrm{Id} / \mathrm{Ig})$ & $\mathrm{La}(\mathrm{nm})$ & $\sigma(\mathrm{La} ; \mathrm{nm})$ \\
\hline Inside & 1.45 & \pm 0.04 & 3.00 & \pm 0.08 \\
\hline Outside & 1.26 & \pm 0.15 & 3.5 & \pm 0.4 \\
\hline
\end{tabular}

FESEM results have been confirmed by AFM analysis (see Fig. 3), which displayed the same bigger and smaller structures, already found in the FESEM scans. AFM maps have shown also an average roughness (RMS) which goes from $2.7 \pm 0.2 \mathrm{~nm}$ for the bigger scan range $\left(3.3 \times 3.3 \mu \mathrm{m}^{2}\right)$ to $1.6 \pm$ $0.4 \mathrm{~nm}$ for the smallest one $\left(370 \times 370 \mathrm{~nm}^{2}\right)$ [35]. This indicates that the film surface is mostly uniform, without significant variations in grains dimensions, all along the coating. To investigate the DLC film's morphology and $\mathrm{sp}^{2} / \mathrm{sp}^{3}$ bonding beyond the surface, we use two additional techniques: Raman spectroscopy and TEM, this last combined with EELS. The first is a well-known technique providing information about carbon allotropes kind and crystalline structure dimensions [36]. Using the 514-nm laser line excitation, we evaluated the Id/Ig ratio for each stent zone (inside and outside). This ratio is correlated with the grain size, using the Tuinstra-Koening formula: $\mathrm{Id}=\operatorname{Ig} 1 / 4 \mathrm{C} \mathrm{JlPLa}^{-1}$ [37], where $\mathrm{C}(\lambda)$ is a constant depending on the laser wavelength [38] and $\mathrm{L}_{\mathrm{a}}$ is the grain size in nanometres. In Table 1, we have reported the values obtained using that relationship. They show that the grains on the inside surfaces of the stent are smaller than those on the outside of the stent, confirming our initial SEM observations. Raman, excited by photons at $514 \mathrm{~nm}$, is mostly sensitive to $\mathrm{sp}^{2}$ sites, due to its much greater cross section than $\mathrm{sp}^{3}$ sites, because it does not excite the higher lying $\sigma$ states. This needs a higher energy. So, in order to confirm the previous results, we performed Raman analysis also with a 458$\mathrm{nm}$ laser line, obtaining Id/Ig values of 1.33 and 1.29 (inner and outer surfaces, respectively) confirming a higher Id/Ig ratio for the inner zone. TEM measurements confirm that the 'cauliflower' structure is present also inside the film. In the same areas, we have also performed EELS analysis, from which we calculated the $\mathrm{sp}^{2} / \mathrm{sp}^{3}$ ratio using the 3-Gaussian method [39], obtaining an amount of $\mathrm{sp}^{3}$ bonds of $41 \%$. On the basis of the above results and discussion, we conclude that the stent coating has a homogeneous, both morphologically and chemically speaking, low-roughness surface, with very small grains (estimated size from 3 to $6 \mathrm{~nm}$ ) and possesses a high amount of $\mathrm{sp}^{3}$ bonds (41\% from 
bulk analysis).
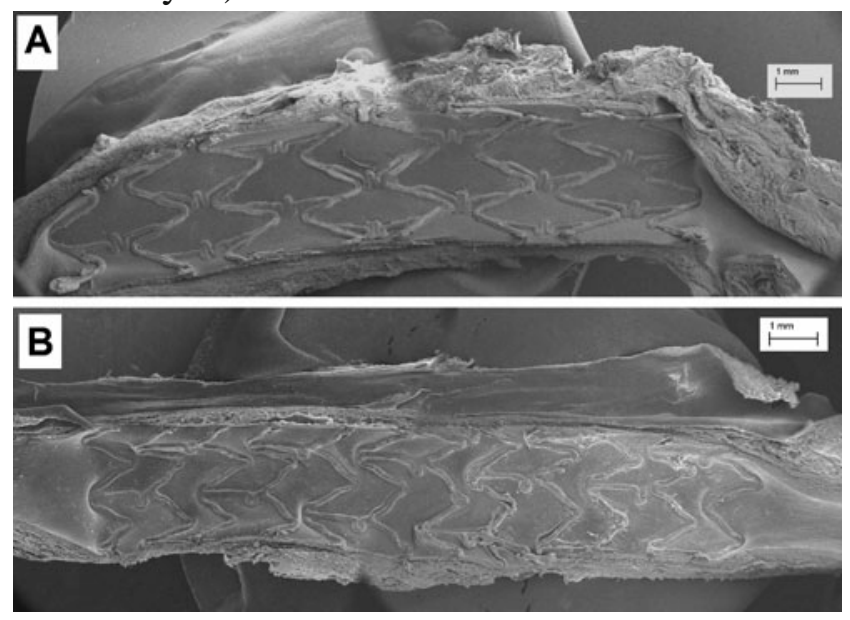

Fig. 4 (A) Avantgarde SEM stent image $(\times 35)$ after 7 days of implantation in a pig coronary artery and metallisation. The image shows a perfect total device endothelisation (98\%). (B) CoCr-uncoated Vision stent after 7 days of implantation in a pig coronary artery and metallisation. Endothelium uncovered stent struts are visible along the whole structure (percentage of endothelisation $65 \%$ )

Analysis of explanted stents

\section{Endothelisation}

The SEM examination of the half-stent surfaces after 7 days of implant revealed no significant presence of thrombotic milieu, in both stent groups. The histological analysis outlined a good endothelial coverage over the strut surfaces, with a carpet of cobblestone-like confluent cells. The percentage of endothelium coverage, measured by histomorphometric assessment, was $98 \%$ in Avantgarde vs. $65 \%$ in Vision (see Fig. 4). It is remarkable to observe that, in Vision stents, the endothelial cells growth was quite inhomogeneous and the lack of early endothelisation was reported even in the presence of wellapposed struts, where cell colonisation is usually observed. On the contrary, in Avantgarde stents endothelial cells also covered not completely well-apposed struts. The stent surface of the control group (see Fig. 5) showed a diffuse fibrin mesh entrapping red blood cells, monocytes, focal giant cells and small luminal adherent thrombi. In the Avantgarde group, no fibrin mesh was observed and only rare monocytes were scattered on the endothelial layer; thrombi were absent and the endothelium was flat and confluent. The endothelial cell stent coverage is found to be in continuity with the native vascular endothelium. This outcome in an in vivo model is in line with the observation of albumin/fibrinogen adsorption of Ma et al. [23] and Fedel et al. [40, 41] for DLC coatings, especially when rich in $\mathrm{sp}^{3}$ bonds. Moreover, Fedel [40] observed that DLC coating showed a competitive and stable albumin passivation against fibrinogen. This condition induces a very limited adhesion and activation of circulating platelets and therefore does not trigger thrombotic clots, as confirmed in our experiment.

Inflammatory responses

Ten Avantgarde and ten Vision stents were selectively explanted at 30 days of follow-up. Stent expansion reached nominal diameter for both devices. The lumen of coronary arteries implanted with Avantgarde stents was lined by a smooth, continuous layer of endothelial cells. Histological sections (see Fig. 6A) showed a slight, uniform neointimal growth, free from significant inflammation and mainly com- posed by smooth muscle cells in a compact proteoglycan stent. 

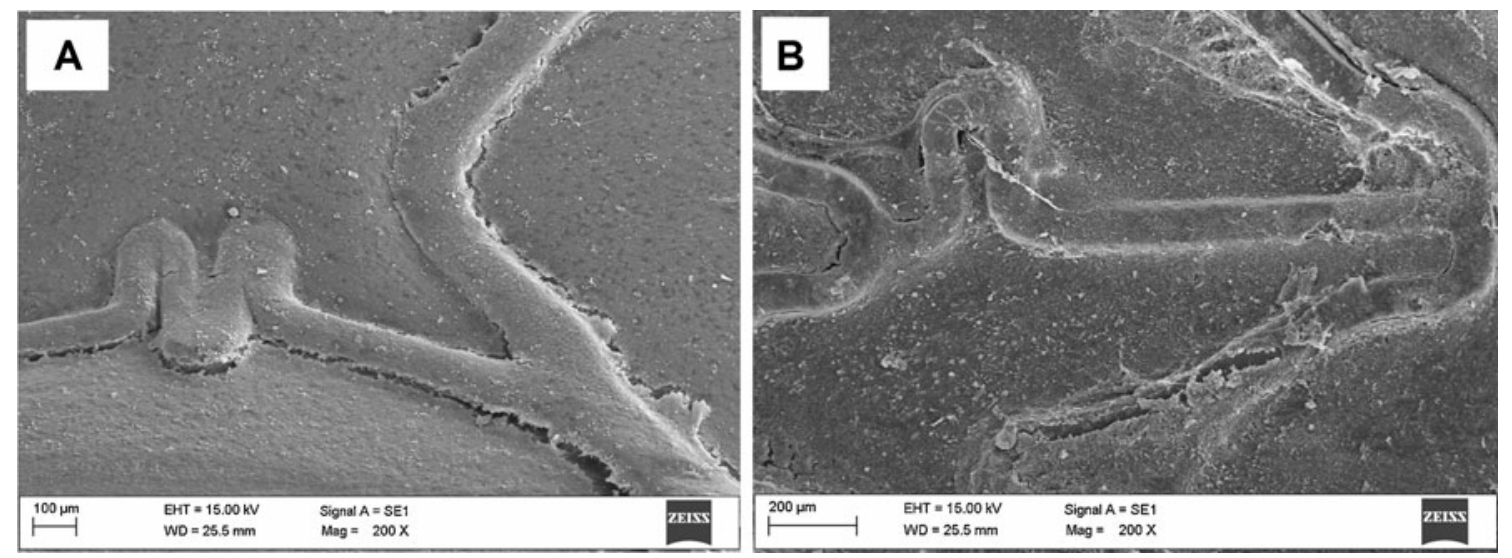

Fig. 5 (A) Avantgarde stent SEM image $(\times 200)$. Detail of the endothelial layer. Polygonal-shaped endothelial cells are clearly recognisable. The cell layer is a continuum between native vessel tissue and new cells covering the metallic structure. Note: the visible layer detachments are due to the SEM technique. (B) CoCr-uncoated Vision

The fibrin net adherent to the metallic structures and vessel endothelium is clearly visible. Several leucocytes and examples of multinucleated giant cells are present.

Fig. 6 Histological section MOVAT $(\times 20$ magnification).

(A) Avantgarde stent at 30 days. Right coronary artery. Thin and regular layer of neointimal tissue. (B) $\quad \mathrm{CoCr}$-uncoated Vision stent at 30 days Left descending artery. Neointimal growth was moderate but slightly asymmetrical.Endothelisa tion appears complete and only few fibrin deposits around struts are detectable. (C) Avantgarde stent at 180 days. Right coronary artery. Neointimal tissue was minimal and no signs of inflammation or fibrin and blood clots are present. (D) $\mathrm{CoCr}-$ uncoated Vision stent at 180 days. Left descending artery. Neointimal tissue has slightly increased and appeared asymmetrical and highly com- posed by extracellular matrix. Fibrin deposits have been reabsorbed and no inflammatory cells were detected
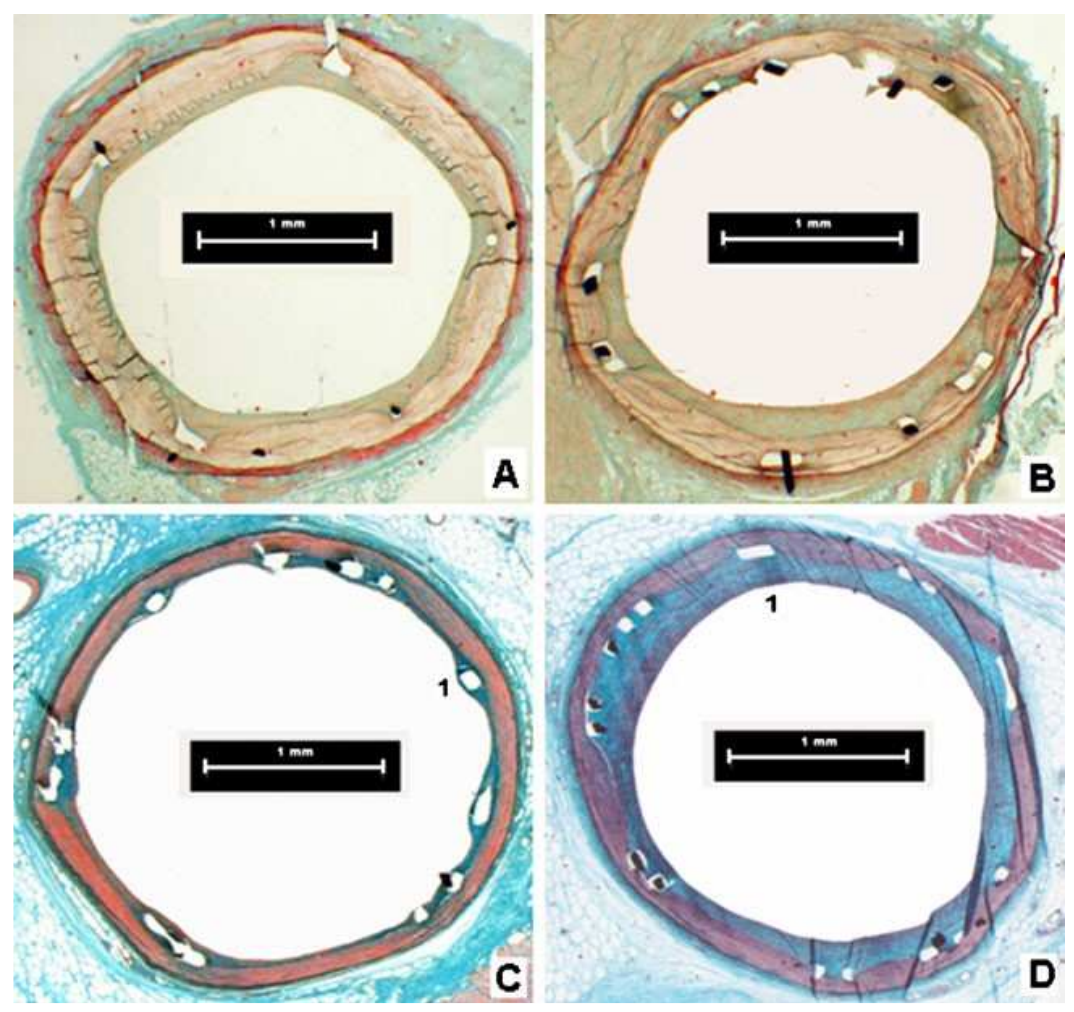
This type of cell tends to occupy the non-endothelised areas of the stent matrix, without blood clots. The elastic lamina appears to be distended and compressed, as it follows the shape of the struts, but fully intact.

The histological samples from the Vision stents at 30 days showed the presence of a continuous endothelial coating. A moderate neointimal proliferation can be seen, irregularly distributed and probably related to mechanical action (see Fig. 6B) caused by the asymmetric distribution of the struts during stent expansion.

Ten animals were electively killed for follow-up after 180 days. These animals had been subjected to double implants for a total of ten Avantgarde and ten Vision stents. All the animals were in good clinical condition at the time of explantation, and angiography confirmed that all of the stents implanted were non-obstructive. The histological images of coronary arteries implanted with Avantgarde showed stabilised repair processes. In fact, the peak inflammatory response is generally found at 30 days after implant, whilst at longer follow-ups a reduction in tissue reaction can be observed. The neointimal layer was regular and thin (see Fig. 6C). The few smooth muscle cells present are embedded in a fibrous connective tissue, which appears to be well-organised in layers. There is no evidence of granulomas and chronic inflammatory cells. Both elastic laminae were intact, though in a number of samples they were slightly compressed following the morphology of the stent struts. As Vision stents are concerned, the neointimal layer appeared thicker and slightly asymmetrical, with occasional macrophages around the stent struts (see Fig. 6D). The elastic laminae were intact in most of the investigated samples, with few exceptions, where the internal elastic lamina was lacerated by some struts.

Histomorphometric analysis showed in both cases a mild neointimal growth and restenotic response. Nonetheless, in the Avantgarde group all measured parameters were lower at 30 days. Such early difference between Avantgarde and Vision increased from 30 to 180 days, reaching statistical significance for the neointimal thickness and area values (see Table 2). This confirms the minimal inflammatory elicitation induced by the DLC coating of the Avantgarde.

Table 2 Histomorphometric analysis results for both stents at 30 and 180 days

\section{0 days}

$\mathrm{n}$

Avantgarde

Vision
180 days

Avantgarde Vision

n number

of

histological

sections

Neointimal area

(mm2)

$10 \quad 1.1 \pm 0.5$

$1.4 \pm 0.8$

$10 \quad 1.0 \pm 0.4 *$

$1.5 \pm 0.4$

$* p<0.05$

(neointimal

area and

neointimal Neointimal

$0.16 \pm 0.06$

thickness (mm)

$10 \quad 0.14 \pm 0.09$

$0.18 \pm 0.11 \quad 10$

$0.10 \pm 0.05 *$

thickness

Avantgarde

vs. Vision) Vessel 
The distinct in vivo inflammatory reaction induced by the two stents, leading to slightly different proliferative responses, can be explained by the surface polishing and DLC coating properties. In fact, this particular carbon film appeared to be composed of homogenous small nanostructures and forming an extremely thin layer. All these characteristics preserving the mirror polished surface of the Avantgarde stent reduced platelet activation, the adhesion of inflammatory cells and the proliferative activation of the smooth muscle cells.

\section{Conclusions}

DLC films deposited by PVD on Co-Cr alloy stents were analysed with respect to their surface morphology (AFM and FESEM), chemical state (XPS), bulk $\mathrm{sp}^{3}$ content (EELS), morphology (TEM) and composition (Raman and EDX). Biological tests were conducted after 7 days in order to verify rapid endothelisation and after 30 and 180 days to investigate inflammatory responses. Our results showed that the iCarbofilm $\mathrm{TM}^{\mathrm{TM}}$ is rich in $\mathrm{sp}^{3}$ bonds $(41 \%)$ and its nano- structured surface is morphologically and chemically homogeneous, thanks also to its thinness which preserves the metal substrate's smooth surface. These characteristics, as mentioned in several papers [23, 41], lead to a selective adsorption of proteins (albumin instead of fibrinogen) and to a very low platelets activation. The chemical and tribological characteristics recommended this new DLC coating for its extremely favourable haemocompatibility and non- inflammatory behaviour. The results of our study confirm this, with the Avantgarde DLC-coated Co-Cr stents demonstrating a more complete and homogenous endothelisation and effective inhibition of fibrin deposits and platelet acti- vation, reducing thrombotic clots. The reduced inflammatory activation of this coating resulted in complete stabilisation of the vessel healing within 30 days and a minimal neointimal proliferation at 180 days.

Acknowledgements This research has been supported by a grant from CID S.p.A (Saluggia, Italy). The authors wish to thank Dr. Pasquino E. and Dr. Grignani A. for their invaluable contribution and fruitful discussions during this paper drafting; Dr. S. Guastella (Poly- technic of Turin, Italy) for his SEM/EDX measurements; Dr. Giusca C. (ATI Centre, UK) for her help during AFM measurements and Dr. Hinder S. (University of Surrey, UK) for his help during XPS measurements.

Disclosure statement Funding has been supported by CID S.p.A (Saluggia, Italy), which has also provided stents for the physical and clinical analysis. The authors are thankful for the contributions of technical support, numerous valuable discussions and research guidance from CID, but we also confirm that there are no known conflicts of interest and that the Company had no influences on our work and results.

\section{References}

1. Mani G, Marc D, Feldman MD, Patel D, Agrawal CM (2007) Coronary stents: a materials perspective. Biomaterials 28:1689-1710

2. Sabbatini L (2005) Analysis of biomaterials. Anal Bioanal Chem 381:529-530

3. Roy RK, Lee KL (2007) Biomedical applications of diamond-like carbon coatings: a review. J Biomed Mater Res B Appl Biomater 83B:72-84

4. Arps JH, Dearnaley G (2004) Diamond and diamond-like carbons. In: Bowlin GL, Wnek G (eds) Encyclopedia of biomaterials and biomedical engineering. Marcel Dekker, New York, pp 446-455

5. Robertson J (2002) Diamond-like amorphous carbon. Mater Sci Eng Rep 37:129-281 
6. Prunotto M, Galloni MR (2005) Stenting: biomaterials in mini- invasive cardiovascular applications. Anal Bioanal Chem 381:531- 533

7. Dearley G, Arps JH (2005) Biomedical applications of diamond- like carbon (DLC) coatings: a review. Surf Coat Technol 200:2518-2524

8. Grill A (2003) Diamond-like carbon coatings as biocompatible materials-an overview. Diamond Relat Mater 12:166-170

9. Maguire PD et al (2005) Mechanical stability, corrosion perfor- mance and bioresponse of amorphous diamond-like carbon for medical stents and guidewires. Diamond Relat Mater 14:1277- 1288

10. Leng Y, Chen J, Yang P, Sun H, Wan G, Huang N (2002) Me- chanical properties and platelet adhesion behaviour of diamond- like carbon films synthesized by pulsed vacuum arc plasma deposition. Surf Sci 531:177-184

11. Paccagnella A, Majni G, Ottaviani G, Arru P, Santi M, Vallana F (1986) Properties of a new carbon film for biomedical applications. Int J Artif Organs 9:127-130

12. Cui F, Li D (2000) A review of investigations on biocompatibility of diamond-like carbon and carbon nitride films. Surf Coat Technol 131:481-487

13. Hauert R (2003) A review of modified DLC coatings for biological applications. Diamond Relat Mater 12:583-589

14. Allen M, Law F, Rushton N (1994) Effects of DLC coatings on macrophages, fibroblasts and osteoblast-like cells in vitro. Clin Mater 17:1-10

15. Sbarbati R, Giannessi D, Cenni MC, Lazzerini G, Verni F, De Caterina R (1991) Pyrolytic carbon coating enhances Teflon and Dacron fabric compatibility with endothelial cell growth. Bioma- terials 14:491-498

16. Jones MI, McColl IR, Grant DM, Parker KG, Parker TL (2000) Protein adsorption and platelet attachment and activation, on TiN, TiC, and DLC coatings on titanium for cardiovascular applica- tions. J Biomed Mater Res 52:413-421

17. Nurdin N, Francois P, Mugnier Y, Krumeich J, Moret M, Aronsson B, Descouts P (2003) Haemocompatibility evaluation of DLC- and SiC-coated surfaces. Eur Cells Mater 5:17-28

18. Jones MI, McColl IR, Grant DM, Parker KG, Parker TL (1999) Haemocompatibility of DLC and TiC-TiN interlayers on titanium. Diamond Relat Mater 8:457-462

19. Linder S, Pinkowski W, Aepfelbacher M (2002) Adhesion, cyto- skeletal architecture and activation status of primary human macro- phages on a diamond-like carbon coated surface. Biomaterials 23:767-773

20. Singh A, Ehteshami G, Massia S, He J, Storer RG, Raupp G (2003) Glial cell and fibroblast cytotoxicity study on plasma- deposited diamond-like carbon coatings. Biomaterials 24:50835089

21. Kelly S, Regan EM, Uney JB, Dick AD, McGeehan JP (2008) The Bristol Biochip Group. Patterned growth of neuronal cells on modified diamond-like carbon substrates. Biomaterials 29:2573-2580

22. Wang H, Xu M, Zhang W, Kwok DTK, Jiang J, Wu Z, Chu PK (2010) Mechanical and biological characteristics of diamond-like carbon coated poly aryl-ether-ether-ketone. Biomaterials 31:81818187

23. Ma WJ et al (2007) DLC coatings: effects of physical and chemical properties on biological response. Biomaterials 28:1620-1628

24. Liu H, Webster TJ (2007) Nanomedicine for implants: a review of studies and necessary experimental tools. Biomaterials 28:354- 369

25. Shirley DA (1972) High-resolution X-ray photoemission spectrum of the valence bands of gold. Phys Rev B 5:4709-4714

26. Merel P, Tabbal M, Chaker M, Moisa S, Margot J (1998) Direct evaluation of the $\mathrm{sp}^{3}$ content in 
diamond-like-carbon films by XPS. Appl Surf Sci 136:105-110

27. Diaz J, Paolicelli G, Ferrer S, Comin F (1996) Separation of the $\mathrm{sp}^{3}$ and $\mathrm{sp}^{2}$ components in the C1s photoemission spectra of amor- phous carbon films. Phys Rev B 54:8064-8069

28. Haerle R, Riedo E, Pasquarello A, Baldereschi A (2001) $\mathrm{sp}^{2} / \mathrm{sp}^{3}$ hybridization ratio in amorphous carbon from $\mathrm{C} 1 \mathrm{~s}$ core-level shifts: X-ray photoelectron spectroscopy and first-principles calculation. Phys Rev B 65:045101-045109

29. Jackson ST, Nuzzo RG (1995) Determining hybridization differ- ences for amorphous carbon from the XPS C1s envelope. Appl Surf Sci 90:195-203

30. Calliari L, Laidani N, Speranza G (1998) X-ray and UV valence band photoemission of carbon films. Surf Interface Anal 26:565-568

31. Speranza G et al (2008) Characterization of UV irradiated nano- crystalline diamond. Diamond Relat Mater 17:1194-1198

32. McFeely FR, Kowalczyk SP, Ley L, Cavell RG, Pollak RA, Shirley DA (1974) X-ray photoemission studies of diamond, graphite, and glassy carbon valence bands. Phys Rev B 9:5268- 5278

33. Gelius U (1972) In: Shirley DA (ed) Electron spectroscopy. North- Holland, Amsterdam, pp 311344

34. Xi T, Gao R, Xu B, Chen L, Luo T, Liu J, Wei Y, Zhong S (2010) In vitro and in vivo changes to PLGA/sirolimus coating on drug eluting stents. Biomaterials 31:5151-5158

35. Horcas I, Fernández R, Gómez-Rodríguez JM, Colchero J, Gómez-Herrero J, Baro AM (2007) WSXM: a software for scan- ning probe microscopy and a tool for nanotechnology. Rev Sci Instrum 78:0137051-0137058

36. Ferrari AC, Robertson J (2000) Interpretation of Raman spectra of disordered and amorphous carbon. Phys Rev B 61:14095-14107

37. Tuinstra F, Koening JL (1970) Raman spectrum of graphite. J Chem Phys 53:1126-1130

38. Matthews MJ, Pimenta MA, Dresselhaus G, Dresselhaus MS, Endo M (1999) Origin of dispersive effects of the Raman D band in carbon materials. Phys Rev B 59:R6585-R6588

39. Ferrari AC et al (2000) Density, $\mathrm{sp}^{3}$ fraction, and cross-sectional structure of amorphous carbon films determined by X-ray reflec- tivity and electron energy-loss spectroscopy. Phys Rev B 62:11089-11103

40. Fedel M, Motta A, Maniglio D, Migliaresi C (2010) Carbon coatings for cardiovascular applications: physico-chemical properties and blood compatibility. J Biomater Appl 25:57-74

41. Fedel M, Motta A, Maniglio D, Migliaresi C (2009) Surface properties and blood compatibility of commercially available diamond-like carbon coatings for cardiovascular devices. J Biomed Mater Res B Appl Biomater 90B:338-349 